\title{
A Naturally Occurring Rexinoid, Honokiol, Can Serve as a Regulator of Various Retinoid X Receptor Heterodimers
}

\author{
Hitoshi Kotani, ${ }^{a, b}$ Hiroki Tanabe, ${ }^{a}$ Hajime Mizukami, ${ }^{b}$ Sakae Amagaya, ${ }^{c}$ and Makoto Inoue*,a \\ ${ }^{a}$ Laboratory of Medicinal Resources, School of Pharmacy, Aichi Gakuin University; 1-100 Kusumoto-cho, Chikusa- \\ ku, Nagoya 464-8650, Japan: ${ }^{b}$ Laboratory of Pharmacognosy, Graduate School of Pharmaceutical Sciences, Nagoya \\ City University; 3-1 Tanabe-dori, Mizuho-ku, Nagoya 467-8603, Japan: and ${ }^{c}$ Department of Kampo Pharmaceutical \\ Sciences, Nihon Pharmaceutical University; 10281 Komuro, Ina-machi, Kita-adachi-gun, Saitama 362-0806, Japan. \\ Received February 21, 2011; accepted October 27, 2011; published online November 2, 2011
}

We investigated the properties of honokiol, a natural rexinoid, as a regulator of retinoid $\mathrm{X}$ receptor (RXR) heterodimers with various partner nuclear receptors (NRs), in comparison with those of the synthetic rexinoid bexarotene. Honokiol alone was hardly capable of activating peroxisome proliferator-activated

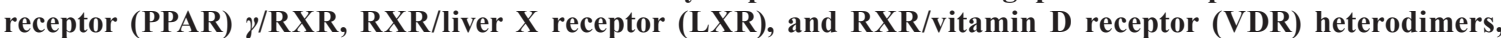
whereas it effectively potentiated their activation by agonists for the partner NRs of the RXR heterodimers. These findings were further supported by increased mRNA and protein levels for the respective NR target genes. Bexarotene alone activated PPAR $/$ RXR and RXR/LXR heterodimers, but not RXR/VDR heterodimers, and facilitated the activation of all three RXR heterodimers by the respective PPAR $\gamma$, LXR, and VDR agonists. When the potencies of honokiol and bexarotene were compared, honokiol was able to serve as a subsidiary agonist in the activation of RXR heterodimers in a similar manner to bexarotene. However, it seemed to potentiate the activation of PPAR $\gamma / R X R$ heterodimers by the PPAR $\gamma$ agonist rosiglitazone more efficiently than bexarotene, and was a less potent RXR agonist than bexarotene. In conclusion, we have demonstrated that honokiol is a rexinoid that possesses distinct properties from bexarotene, and mainly has subsidiary roles in the activation of RXR heterodimers by potentiating the activation of RXR heterodimers by agonists for the partner NRs.

Key words honokiol; rexinoid; retinoid X receptor agonist; liver X receptor; peroxisome proliferator-activated receptor; vitamin $\mathrm{D}$ receptor

Retinoid $\mathrm{X}$ receptor $(\mathrm{RXR})$ is a member of the nuclear receptor (NR) superfamily of ligand-activated transcription factors, and plays a critical role in the regulation of some NRs because it forms heterodimers with certain other family members in addition to homodimers that are involved in the control of a variety of physiologic processes. ${ }^{1-3)}$ The heterodimeric partners of RXR have been classified as either permissive or nonpermissive NRs. ${ }^{4,5)}$ The RXR heterodimers with permissive NRs, including peroxisome proliferator-activated receptor (PPAR), liver $X$ receptor (LXR), and farnesoid $X$ receptor (FXR), can be activated by RXR agonists even in the absence of an agonist for the partner NR. Importantly, when both the partner NR and RXR are activated, they act in an additive or synergistic manner. In contrast, the RXR heterodimers with nonpermissive NRs, including retinoic acid receptor (RAR), thyroid hormone receptor (TR), and vitamin $\mathrm{D}$ receptor (VDR), cannot be activated by RXR agonists and are only activated by an agonist for the partner NR. However, recent evidence has indicated that $\mathrm{RXR} / \mathrm{RAR}, \mathrm{RXR} / \mathrm{VDR}$, and RXR/TR heterodimers, which have been considered to be nonpermissive, can be activated by RXR agonists depending on factors such as the tissue specificity, cellular environment, or ability of rexinoids to recruit various coactivators or corepressors, regardless of the presence or absence of a partner NR agonist. ${ }^{6-8)}$ This diversity in the regulation of gene transcription by RXR is linked to the numerous effects exerted by RXR agonists.

A class of compounds that selectively bind and activate RXRs relative to RARs are collectively referred to as rexinoids, and have been found to exert beneficial effects in animal models of insulin resistance, type 2 diabetes, obesity, and atherosclerosis. $^{9,10)}$ Rexinoids are also essential tools for in- vestigating the permissiveness of RXR heterodimer partners, because natural RXR agonists, including 9-cis-retinoic acid, phytanic acid, and docosahexaenoic acid, are not selective for RXR and also activate other NRs. ${ }^{1-13)}$ However, the use of synthetic rexinoids often raises the issue of whether the endogenous agonists have similar effects in vivo. In this context, compounds that only recognize RXRs are very valuable for deciphering the roles played by these receptors and their ligand-dependent activities and for better understanding of the relationships between the partners in RXR heterodimers. Although rexinoids have therapeutic value and may offer enhanced potency through the activation of permissive heterodimers, this advantage is likely to be offset by the capacities of rexinoids to raise triglyceride levels, suppress the thyroid hormone axis, and induce hepatomegaly. ${ }^{14-16)}$ However, these adverse effects do not appear to be common among all rexinoids, suggesting that RXR-specific agonists with improved pharmacological properties may eventually become available as additional treatment options for the current epidemic of obesity, insulin resistance, type 2 diabetes, and all the associated metabolic sequelae.

In a previous study, we found that honokiol, a neolignan in Magnolia obovata, is a naturally occurring rexinoid that can activate $\mathrm{RXR}$, but not $\mathrm{RAR}, \operatorname{PPAR} \gamma, \operatorname{PPAR} \delta$, or $\mathrm{LXR} .{ }^{17)}$ Therefore, the present study was undertaken to characterize the properties of the natural rexinoid honokiol by examining its regulatory effects toward various RXR heterodimers, with the aim of developing novel rexinoids that lack the adverse effects associated with the synthetic rexinoids currently in clinical use. We found that honokiol as a natural rexinoid possesses the capacity to potentiate the activation of RXR heterodimers by agonists for the partner NRs regardless of their 
permissiveness or nonpermissiveness, whereas honokiol alone can only activate RXR heterodimers with very slight efficacy.

\section{MATERIALS AND METHODS}

Materials T0901317 (LXR agonist) and calcitriol (VDR agonist) were purchased from Cayman Chemicals (Ann Arbor, MI, U.S.A.). Rosiglitazone (PPAR $\gamma$ agonist) was obtained from Alexis Biochemicals (San Diego, CA, U.S.A.). Honokiol and bexarotene were purchased from Kishida (Osaka, Japan) and Toronto Research Chemicals Inc. (North York, Canada), respectively.

Cell Cultures Mouse 3T3-L1 preadipocytes, human embryonic kidney (HEK) 293 cells, HLE human hepatoma cells, and Caco-2 human epithelial colorectal adenocarcinoma cells were provided by RIKEN BRC (Tsukuba, Japan) through the National Bio-Resource Project of the Ministry of Education, Culture, Sports, Science and Technology of Japan. 3T3-L1 preadipocytes were maintained in Dulbecco's modified Eagle's medium (DMEM) supplemented with $10 \%$ bovine calf serum (Safc Biosciences, KS, U.S.A.), $100 \mathrm{U} / \mathrm{mL}$ of penicillin (Sigma-Aldrich, MO, U.S.A.), and $100 \mu \mathrm{g} / \mathrm{mL}$ of streptomycin (Sigma-Aldrich) at $37^{\circ} \mathrm{C}$ in a humidified atmosphere of $5 \%$ $\mathrm{CO}_{2}$ in air. For differentiation of 3T3-L1 preadipocytes, cells at $2 \mathrm{~d}$ after reaching confluency were incubated in differentiation medium comprising DMEM supplemented with 10\% fetal bovine serum (FBS) (Nichirei Biosciences Inc., Tokyo, Japan), $500 \mu \mathrm{M}$ 3-isobutyl-1-methylxanthine (Sigma-Aldrich), $10 \mu \mathrm{g}$ / $\mathrm{mL}$ of insulin (Sigma-Aldrich), and $100 \mathrm{~nm}$ dexamethasone (Nacalai Tesque Inc., Kyoto, Japan). After $2 \mathrm{~d}$, the culture medium was changed to DMEM containing $10 \mu \mathrm{g} / \mathrm{mL}$ of insulin and $10 \%$ FBS. The medium was replaced again with fresh DMEM containing $10 \%$ FBS after $2 \mathrm{~d}$. The adipocytes were used at $8-10 \mathrm{~d}$ after the initiation of differentiation. HLE and Caco-2 cells were maintained in DMEM supplemented with $10 \% \mathrm{FBS}, 100 \mathrm{U} / \mathrm{mL}$ of penicillin, and $100 \mu \mathrm{g} / \mathrm{mL}$ of streptomycin at $37^{\circ} \mathrm{C}$ in a humidified atmosphere of $5 \% \mathrm{CO}_{2}$ in air. HEK293 cells were maintained in minimum essential medium containing 10\% FBS and non-essential amino acids (SigmaAldrich), $100 \mathrm{U} / \mathrm{mL}$ of penicillin, and $100 \mu \mathrm{g} / \mathrm{mL}$ of streptomycin at $37^{\circ} \mathrm{C}$ in a humidified atmosphere of $5 \% \mathrm{CO}_{2}$ in air.

Quantitative Reverse Transcription-Polymerase Chain Reaction (RT-PCR) Total RNA was isolated from the cultured cells using RNAiso Plus (Takara Bio Inc., Otsu, Ja- pan). Following treatment of the RNA samples with DNase (Invitrogen, Carlsbad, CA, U.S.A.), first-strand cDNA was synthesized from $0.5 \mu \mathrm{g}$ of total RNA using an oligo(dT) $)_{20}$ RT primer and ReverTra Ace (Toyobo, Tokyo, Japan) according to the manufacturer's instructions. Quantitative real-time PCR (SYBR green) analysis was performed using a TP800 Thermal Cycler Dice ${ }^{\circledR}$ Real-time System (Takara Bio Inc.). The mRNA expression levels were normalized by the $\beta$-actin mRNA levels and calculated according to the delta-delta $\mathrm{Ct}$ method. The primer sequences used in the present study are listed in Table 1.

Western Blot Analysis After a 24-h incubation period, HLE or HEK293 cells were harvested and lysed in $50 \mu \mathrm{L}$ of RIPA buffer (25 mm Tris-HCl pH 7.4, 1\% NP-40, $150 \mathrm{~mm}$ $\mathrm{NaCl}, 0.1 \%$ sodium dodecyl sulfate (SDS), $1 \%$ sodium deoxycholate, $5 \mathrm{~mm}$ ethylenediaminetetraacetic acid (EDTA), and protease inhibitor cocktail tablets (Roche Diagnostics, Tokyo, Japan)) or membrane protein extraction buffer $(10 \mathrm{~mm}$ Tris- $\mathrm{HCl} \mathrm{pH} 8.0,0.1 \%$ Triton $\mathrm{X}-100,0.15 \mathrm{~mm} \mathrm{KCl}, 5 \mathrm{~mm}$ mercaptoethanol, $1.3 \mathrm{~mm}$ EDTA, and protease inhibitor cocktail tablets) on ice. The lysates were centrifuged at $12000 \times \boldsymbol{g}$ for $15 \mathrm{~min}$ at $4^{\circ} \mathrm{C}$, and the resulting supernatants were assayed for their protein concentrations (Bradford Assay; Bio-Rad Laboratories, Hercules, CA, U.S.A.). The supernatants $(20 \mu \mathrm{g}$ protein) were separated by SDS-PAGE using a $12 \%$ gel and transferred onto polyvinylidene fluoride membranes (Millipore, Billerica, MA, U.S.A.). After blocking with 5\% powdered skin milk in Tris-buffered saline (TBS) for $2 \mathrm{~h}$, the membranes were incubated with primary antibodies against angiopoietin-like protein (Angptl)-4 (1:2000 dilution; Abnova Corporation, CA, U.S.A.), ATP-binding cassette transporter A1 (ABCA1) (MABI 98-2; 1:50 dilution; kind gift from Dr. S. Yokoyama, Chubu University, Aichi, Japan) or cytochrome P450 (CYP) 24A1 (1:2000 dilution; Abnova Corporation) in TBS containing $1 \%$ powdered skim milk and $0.05 \%$ Tween-20 overnight at $4^{\circ} \mathrm{C}$. The membranes were then washed in three changes of wash buffer $(0.05 \%$ Tween-20 in TBS) and incubated with an alkaline phosphatase-conjugated anti-mouse or anti-rat immunoglobulin G (IgG) secondary antibody (Santa Cruz Biotechnology, Santa Cruz, CA, U.S.A.) in TBS containing $1 \%$ powdered skim milk and $0.05 \%$ Tween-20 for $1 \mathrm{~h}$ at room temperature. The membranes were thoroughly washed in three changes of wash buffer, and the bound antibodies were detected using CDP-Star (Applied Biosystems, Foster

Table 1. Specific Primer Sequences Used for Quantitative Real-Time RT-PCR

\begin{tabular}{|c|c|c|c|c|c|c|c|c|c|c|c|c|c|c|c|c|c|c|}
\hline \multirow[b]{2}{*}{ Human ABCA1 } & \multicolumn{9}{|c|}{ Forward primer $\left(5^{\prime}-3^{\prime}\right)$} & \multicolumn{9}{|c|}{ Reverse primer $\left(5^{\prime}-3^{\prime}\right)$} \\
\hline & ATG & TCC & $\mathrm{AGT}$ & $\mathrm{CCA}$ & GTA & ATG & GTT & $\mathrm{CTG}$ & $\mathrm{T}$ & CGA & GAT & ATG & GTC & CGG & $\mathrm{ATT}$ & $\mathrm{GC}$ & & \\
\hline Human ANGPTL4 & CGT & $\mathrm{ACC}$ & СTT & $\mathrm{CTC}$ & $\mathrm{CAC}$ & TTG & GG & & & $\mathrm{GCT}$ & CTT & GGC & CGA & GTT & $\mathrm{CTT}$ & G & & \\
\hline Human CYP24A1 & TGA & ACG & TTG & $\mathrm{GCT}$ & TCA & GGA & GAA & & & AGG & GTG & $\mathrm{CCT}$ & GAG & TGT & AGC & ATC & & \\
\hline Mouse ABCA1 & $\mathrm{AAT}$ & $\mathrm{TCT}$ & CAA & GTG & $\mathrm{CAA}$ & $\mathrm{ACA}$ & $\mathrm{CTT}$ & CTG & G & GAG & GCA & TAT & $\mathrm{GCT}$ & TGC & GGT & $\mathrm{ACA}$ & & \\
\hline Mouse ABCG1 & GTC & TCA & GCC & TTC & TAA & AGT & TCC & $\mathrm{TC}$ & & TCT & СTC & GAA & GTG & $\mathrm{AAT}$ & GAA & ATT & TAT & CG \\
\hline Mouse apoE & TGA & $\mathrm{ACC}$ & $\mathrm{GCT}$ & $\mathrm{TCT}$ & GGG & ATT & $\mathrm{AC}$ & & & TCT & TGT & GTG & $\mathrm{ACT}$ & TGG & GAG & $\mathrm{C}$ & & \\
\hline Mouse GLUT4 & $\mathrm{CCC}$ & CCG & ATA & $\mathrm{CCT}$ & CTA & $\mathrm{CAT}$ & $\mathrm{CAT}$ & $\mathrm{C}$ & & $\mathrm{GCA}$ & TCA & GAC & $\mathrm{ACA}$ & TCA & GCC & CAG & & \\
\hline Mouse aP2 & $A A A$ & TCA & CCG & CAG & ACG & $\mathrm{ACA}$ & GG & & & $\mathrm{TCC}$ & $\mathrm{ATC}$ & $\mathrm{CCA}$ & СTT & $\mathrm{CTG}$ & $\mathrm{CAC}$ & $\mathrm{CT}$ & & \\
\hline Mouse adiponectin & $\mathrm{ACA}$ & AGG & $\mathrm{CCG}$ & TTC & $\mathrm{TCT}$ & TCA & $\mathrm{CC}$ & & & $\mathrm{CCA}$ & GAT & GGA & GGA & GCA & CAG & $A G$ & & \\
\hline Human TRPV6 & $\mathrm{GCT}$ & $\mathrm{ACT}$ & $\mathrm{TCA}$ & GGA & AGC & CTA & CAT & G & & TGT & $\mathrm{CCA}$ & AAG & $\mathrm{AAG}$ & CGA & GTG & $\mathrm{ACC}$ & & \\
\hline Human calbindin D9k & $\mathrm{CTG}$ & AGC & $\mathrm{ACT}$ & GGA & GGA & AGA & GC & & & $\mathrm{ACC}$ & AGA & GAC & $\mathrm{TTT}$ & GGG & GGA & $\mathrm{TT}$ & & \\
\hline Mouse $\beta$-actin & CAT & $\mathrm{CCG}$ & TAA & AGA & $\mathrm{CCT}$ & CTA & TGC & CAA & $\mathrm{C}$ & ATG & GAG & $\mathrm{CCA}$ & $\mathrm{CCG}$ & ATC & $\mathrm{CAC}$ & A & & \\
\hline Human $\beta$-actin & $\mathrm{ATT}$ & GCC & GAC & AGG & ATG & CAG & $\mathrm{AA}$ & & & $\mathrm{ACA}$ & TCT & GCT & GAA & AGG & TGG & $\mathrm{ACA}$ & G & \\
\hline
\end{tabular}


(A)

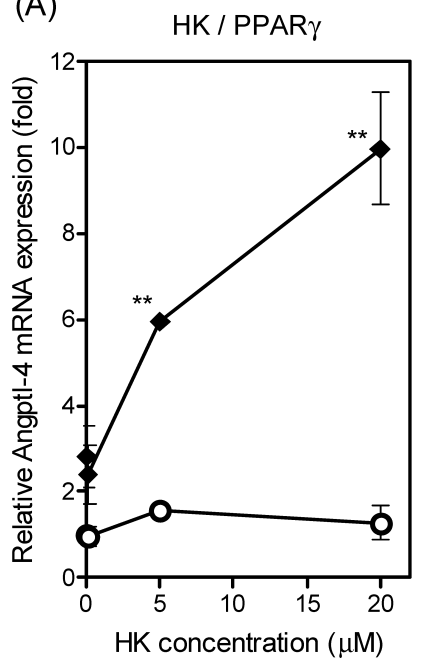

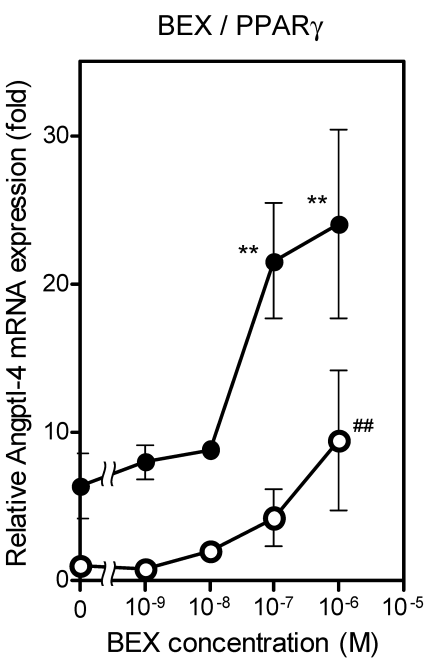

(B)

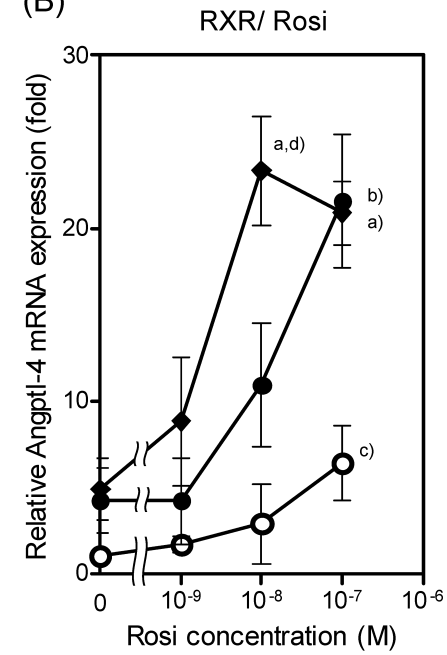

Fig. 1. Effects of Honokiol or Bexarotene in Combination with Rosiglitazone on the Induction of the PPAR $\gamma$ Target Gene Angptl-4

(A) HLE cells were treated with increasing concentrations of honokiol (HK) or bexarotene (BEX) in the absence (open circles) or presence (filled diamonds and circles) of a fixed concentration of the PPAR $\gamma$ agonist rosiglitazone (Rosi; $0.1 \mu \mathrm{M}$ ). (B) HLE cells were treated with increasing concentrations of Rosi in the absence (open circles) or presence of a fixed concentration of the RXR agonist HK (filled diamonds; $20 \mu \mathrm{M}$ ) or BEX (filled circles; $0.1 \mu \mathrm{M}$ ). After $24 \mathrm{~h}$ of incubation, the mRNA levels of Angptl-4 were measured by quantitative real-time RT-PCR, normalized by the $\beta$-actin levels, and expressed as the fold inductions relative to the levels in vehicle-treated cells. The data shown are the means \pm S.D. of three wells from a representative of three independent experiments that produced similar results. $* * p<0.01 v s$. the mRNA levels in cells treated with Rosi in the absence of RXR agonists. a) $p<0.01 v s$. the mRNA levels in cells treated with HK $(20 \mu \mathrm{M})$ in the absence of Rosi. ${ }^{b} p<0.01 v s$. the mRNA levels in cells treated with BEX $(0.1 \mu \mathrm{M})$ in the absence of Rosi. ${ }^{\mathrm{c}} p<0.05,{ }^{\#} p<0.01$ vs. the mRNA levels in cells treated with vehicle. ${ }^{\mathrm{d})} p<0.01 v s$. the mRNA levels in cells treated with $\operatorname{BEX}(0.1 \mu \mathrm{M})$ in the presence of $10^{-8} \mathrm{M}$ Rosi.

(A)

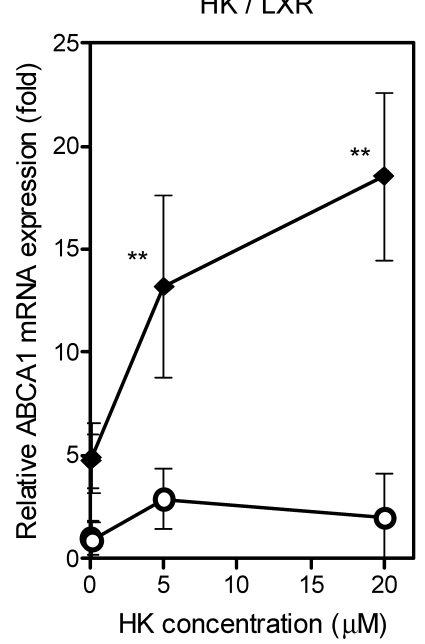

BEX / LXR

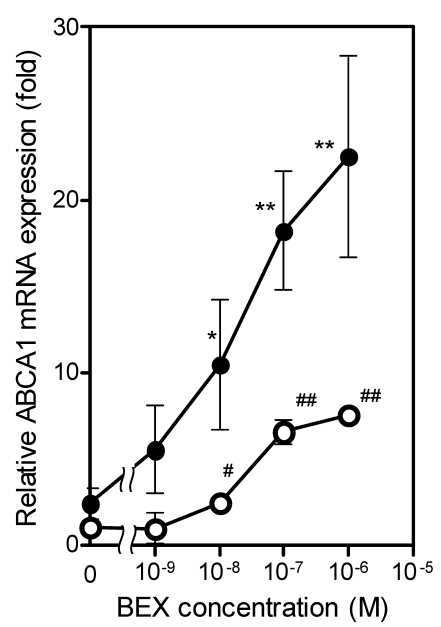

(B)

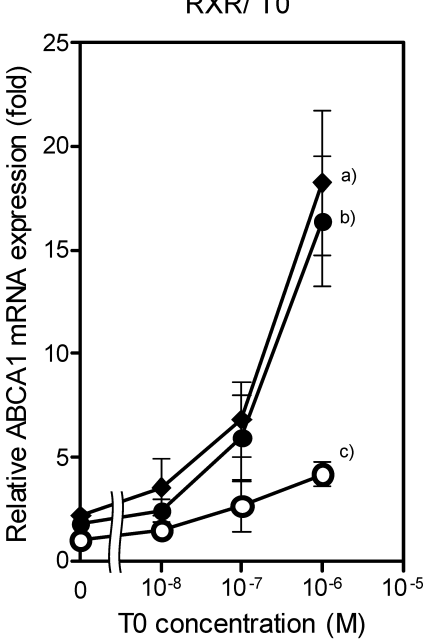

Fig. 2. Effects of Honokiol or Bexarotene in Combination with T0901317 on the Induction of the LXR Target Gene ABCA1

(A) HLE cells were treated with increasing concentrations of honokiol (HK) or bexarotene (BEX) in the absence (open circles) or presence (filled diamonds and circles) of a fixed concentration of the LXR agonist T0901317 (T0; $1 \mu \mathrm{M})$. (B) HLE cells were treated with increasing concentrations of T0 in the absence (open circles) or presence of a fixed concentration of HK (filled diamonds; $20 \mu \mathrm{m}$ ) or BEX (filled circles; $0.1 \mu \mathrm{m}$ ). After $24 \mathrm{~h}$ of incubation, the mRNA levels of ABCA1 were measured as described in the legend to Fig. 1. The data shown are the means \pm S.D. of three wells from a representative of three independent experiments that produced similar results. ${ }^{*} p<0.05$, ${ }^{* *} p<0.01 v s$. the mRNA levels in cells treated with T0 in the absence of RXR agonists. ${ }^{a} p<0.01 v s$. the mRNA levels in cells treated with HK (20 $\left.\mu \mathrm{m}\right)$ in the absence of T0. ${ }^{\text {b) }} p<0.01 v s$. the mRNA levels in cells treated with BEX $(0.1 \mu \mathrm{M})$ in the absence of T0. ${ }^{\#} p<0.05,{ }^{\# \#} p<0.01,{ }^{\mathrm{c})} p<0.01 v s$. the mRNA levels in cells treated with vehicle.

City, CA, U.S.A.) as a substrate for alkaline phosphatase. The protein concentrations were determined using an LAS-3000 mini system (Fujifilm, Tokyo, Japan).

Statistical Analysis Data are presented as means \pm S.D. Differences between values were evaluated for statistical significance by one-way analysis of variance (ANOVA), followed by Bonferroni's $t$-test. Values of $p<0.05$ were considered to indicate statistical significance.

\section{RESULTS}

Comparison of the Properties of Honokiol and Bexarotene for the Induction of PPAR $\gamma$ Target Gene Expression in the Presence or Absence of the PPAR $\gamma$ Agonist Rosiglitazone We previously reported that honokiol is a natural rexinoid that does not activate $\operatorname{PPAR} \gamma, \operatorname{PPAR} \delta$, or $\mathrm{LXR}^{17)}$ In the present study, we sought to delineate the properties of honokiol as a rexinoid in terms of the activation of various RXR heterodimers with permissive or nonpermissive partner 
(A)

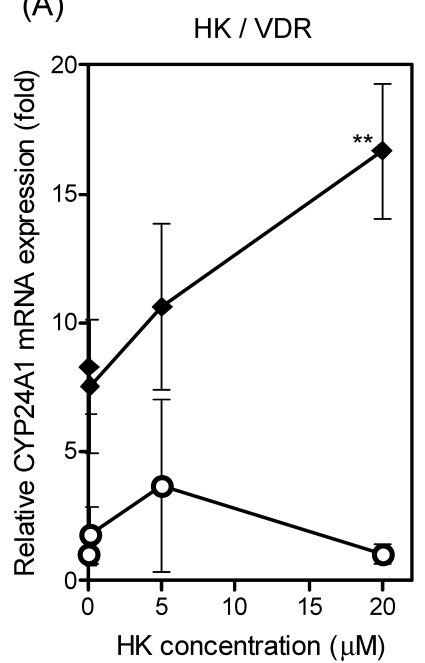

$\mathrm{BEX} / \mathrm{VDR}$

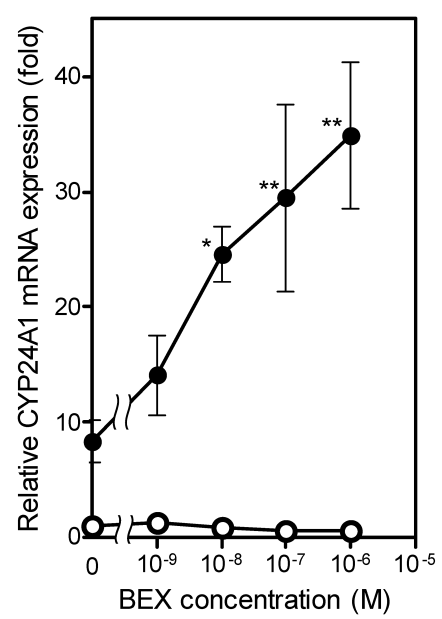

(B)

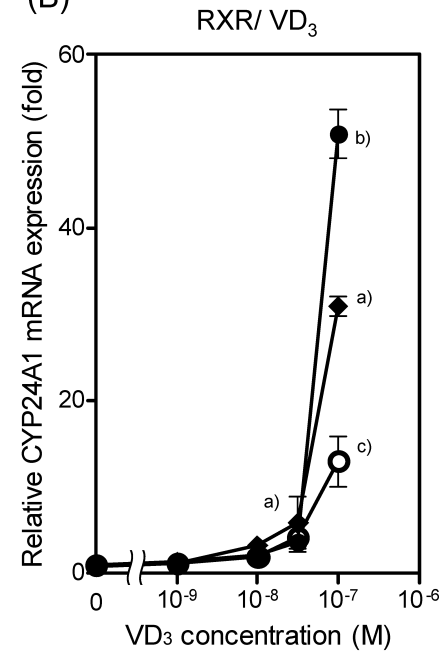

Fig. 3. Effects of Honokiol or Bexarotene in Combination with Calcitriol on the Induction of the VDR Target Gene CYP24A1

(A) HLE cells were treated with increasing concentrations of honokiol (HK) or bexarotene (BEX) in the absence (open circles) or presence (filled diamonds and circles) of a fixed concentration of the VDR agonist calcitriol $\left(\mathrm{VD}_{3} ; 0.1 \mu \mathrm{M}\right.$ ). (B) HLE cells were treated with increasing concentrations of VD in the absence (open circles) or presence of a fixed concentration of HK (filled diamonds; $20 \mu \mathrm{M}$ ) or BEX (filled circles; $0.1 \mu \mathrm{M}$ ). After $24 \mathrm{~h}$ of incubation, the mRNA levels of CYP24A1were measured as described in the legend to Fig. 1. The data shown are the means \pm S.D. of three wells from a representative of three independent experiments that produced similar results. ${ }^{*} p<0.05,{ }^{*} p<0.01 v s$. the mRNA levels in cells treated with $\mathrm{VD}_{3}$ in the absence of RXR agonists. ${ }^{\text {a) }} p<0.01 v s$. the mRNA levels in cells treated with HK (20 $\left.\mu \mathrm{M}\right)$ in the absence of $\mathrm{VD}_{3} .{ }^{\mathrm{b}} p<0.01 \mathrm{vs}$. the mRNA levels in cells treated with BEX $(0.1 \mu \mathrm{M})$ in the absence of $\mathrm{VD}_{3} .{ }^{c} p<0.01 v s$. the mRNA levels in cells treated with vehicle.
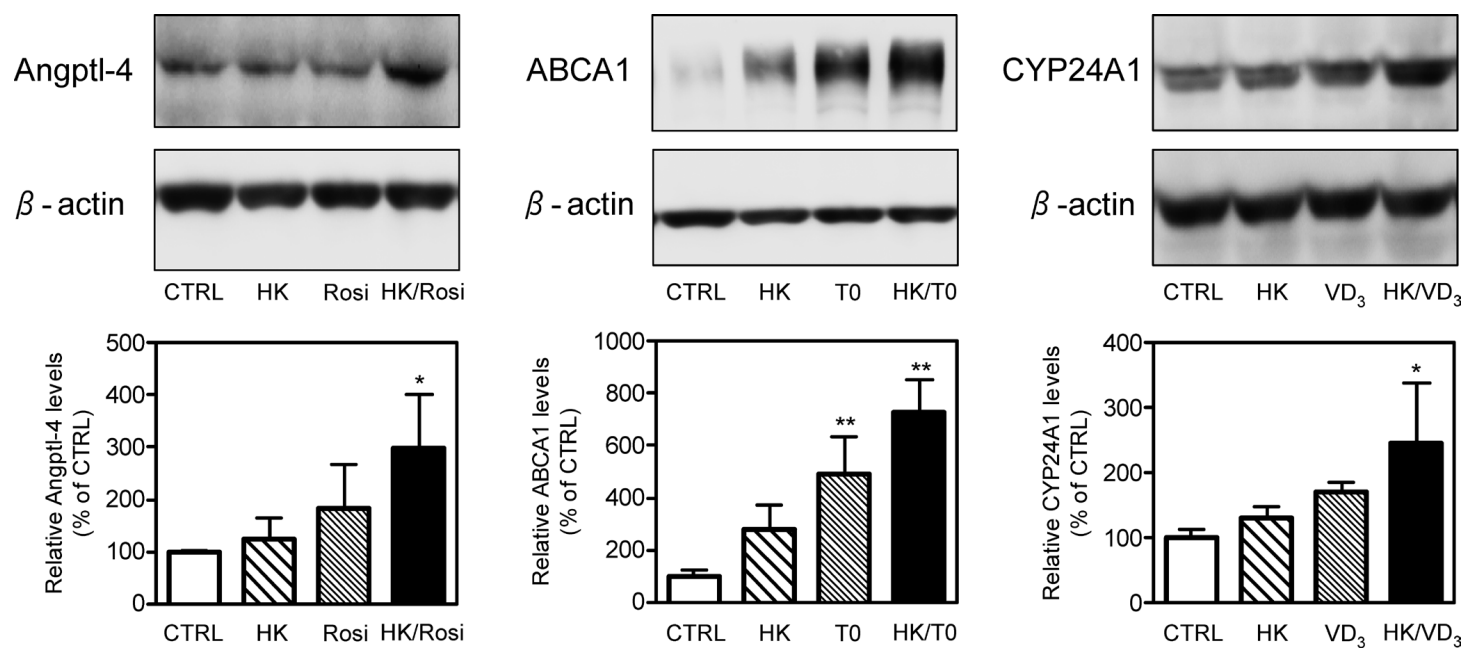

Fig. 4. Effects of Honokiol on the Induction of Angptl-4, ABCA1, and CYP24A1 Proteins

HLE cells were treated with honokiol $(\mathrm{HK} ; 20 \mu \mathrm{M})$ or rosiglitazone (Rosi; $0.1 \mu \mathrm{M})$ alone or with a combination of HK $(20 \mu \mathrm{M})$ and Rosi $(0.1 \mu \mathrm{M})$ for the induction of Angptl-4 protein. HLE cells were treated with HK $(20 \mu \mathrm{M})$ or T0901317 (T0; $1 \mu \mathrm{M})$ alone or with a combination of $\mathrm{HK}(20 \mu \mathrm{M})$ and T0 $(1 \mu \mathrm{M})$ for the induction of ABCA1 protein. HEK 293 cells were treated with $\mathrm{HK}(20 \mu \mathrm{M})$ or calcitriol $\left(\mathrm{VD}_{3} ; 0.1 \mu \mathrm{M}\right)$ alone or with a combination of $\mathrm{HK}(20 \mu \mathrm{M})$ and $\mathrm{VD},(0.1 \mu \mathrm{M})$ for the induction of CYP24A1 protein. After $24 \mathrm{~h}$ of incubation, the protein levels were determined by Western blot analysis. The data shown are representative of three independent experiments that produced similar results. $* p<0.05, * * p<0.01 v s$. the vehicle control (CTRL).

NRs compared with the synthetic rexinoid bexarotene. First, we examined the effects of honokiol and bexarotene on the induction of a PPAR $\gamma$ target gene, Angptl-4, alone or in the presence of the PPAR $\gamma$ agonist rosiglitazone in HLE human hepatoma cells. As shown in Fig. 1A, honokiol alone did not significantly increase the mRNA level of Angptl-4 until the concentration of $20 \mu \mathrm{M}$, while it synergistically increased the mRNA level of Angptl-4 in a dose-dependent manner in the presence of $0.1 \mu \mathrm{M}$ rosiglitazone. In contrast, bexarotene alone significantly increased the mRNA level of Angptl-4 in a dose-dependent manner, and its synergistic effect with $0.1 \mu \mathrm{M}$ rosiglitazone was much lower than that of honokiol. Next, we examined the dose-dependent effects of rosiglitazone in the presence or absence of honokiol $(20 \mu \mathrm{M})$ or bexarotene $(0.1 \mu \mathrm{M})$, both of which were used at almost the concentration required to reach a plateau in the activation of $\operatorname{PPAR} \gamma / \mathrm{RXR}$ heterodimers. In the presence of honokiol, rosiglitazone significantly and synergistically augmented the mRNA level of Angptl-4 even at concentrations of $10^{-9}$ and $10^{-8} \mathrm{M}$, while in the presence of bexarotene, rosiglitazone increased the mRNA level of Angptl-4 less effectively (Fig. 1B).

Comparison of the Properties of Honokiol and Bexarotene for the Induction of LXR Target Gene Expression in the Presence or Absence of the LXR Agonist T0901317 For RXR/LXR heterodimers, honokiol alone failed to increase the mRNA level of an LXR target gene, 

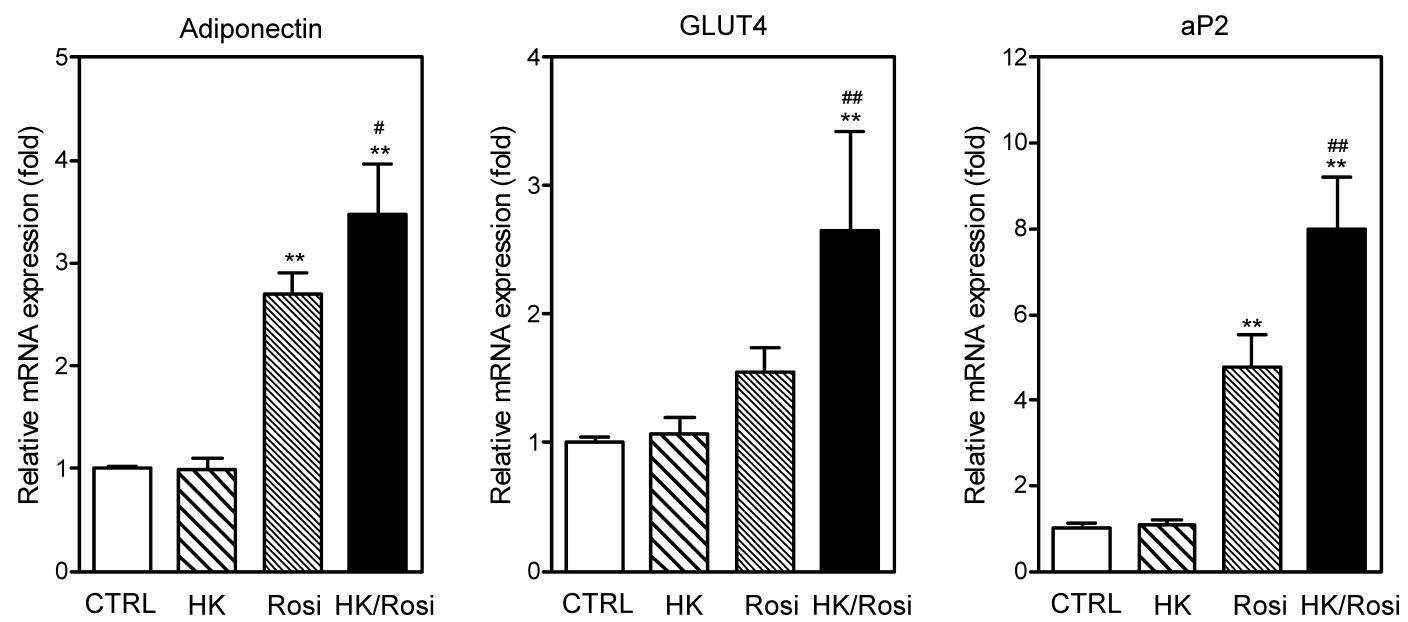

Fig. 5. Effects of Honokiol and a PPAR $\gamma$ Agonist on the Induction of PPAR $\gamma$ Target Genes in 3T3-L1 Adipocytes

3T3-L1 adipocytes were treated with honokiol (HK; $20 \mu \mathrm{M})$ or rosiglitazone (Rosi; $0.1 \mu \mathrm{M}$ ) alone or with a combination of HK (20 $\mu \mathrm{M})$ and Rosi $(0.1 \mu \mathrm{M})$ for $24 \mathrm{~h}$. After the incubation, the mRNA levels of adiponectin, GLUT4, and aP2 were measured by quantitative real-time RT-PCR, normalized by the $\beta$-actin levels, and expressed as the fold inductions relative to the levels in vehicle-treated cells. The data shown are the means \pm S.D. of three wells from a representative of three independent experiments that produced similar results. ${ }^{* *} p<0.01 v s$. the vehicle control (CTRL); ${ }^{\#} p<0.05,{ }^{\# \#} p<0.01 v s$. the Rosi group.
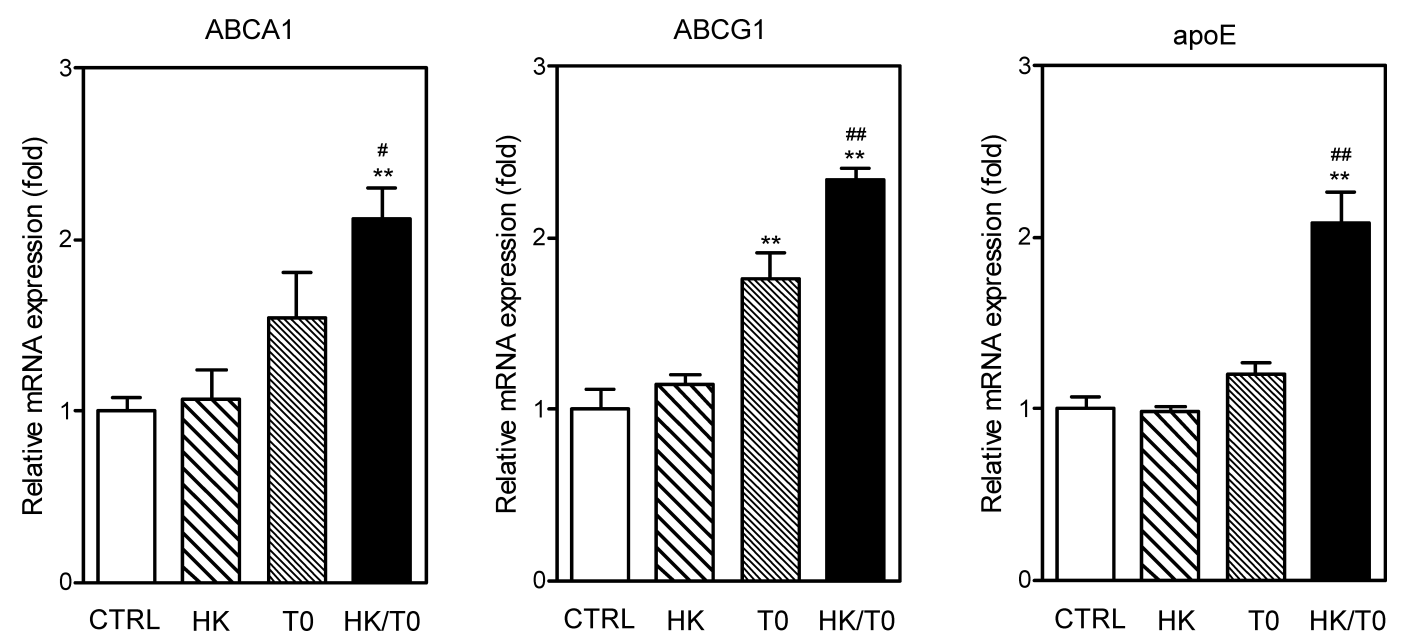

Fig. 6. Effects of Honokiol and an LXR Agonist on the Induction of LXR Target Genes in 3T3-L1 Adipocytes

3T3-L1 adipocytes were treated with honokiol (HK; $20 \mu \mathrm{M})$ or T0901317 (T0; $1 \mu \mathrm{M})$ alone or with a combination of HK (20 $\mu \mathrm{M})$ and T0 $(1 \mu \mathrm{M})$ for $24 \mathrm{~h}$. After the incubation, the mRNA levels of ABCA1, ABCG1, and apoE were measured by quantitative real-time RT-PCR, normalized by the $\beta$-actin levels, and expressed as the fold inductions relative to the levels in vehicle-treated cells. The data shown are the means \pm S.D. of three wells from a representative of three independent experiments that produced similar results. ${ }^{*} p<00.01 v s$. the vehicle control (CTRL); ${ }^{\#} p<0.05,{ }^{\# \#} p<0.01$ vs. the T0 group.

ABCA1, in HLE cells, while it significantly increased the mRNA level of ABCA1 in a dose-dependent manner in the presence of the LXR agonist T0901317 (1 $\mu$ M) (Fig. 2A). On the other hand, bexarotene alone significantly increased the mRNA level of ABCA1 in a dose-dependent manner, and further potentiated the induction of the mRNA in the presence of T0901317. When the dose-dependent effects of T0901317 were assessed in the presence or absence of rexinoids, T0901317 synergistically stimulated similar increases in the mRNA level of ABCA1 in the presence of honokiol or bexarotene, compared with the levels without RXR agonists (Fig. 2B).

Comparison of the Properties of Honokiol and Bexarotene for the Induction of VDR Target Gene Expression in the Presence or Absence of the VDR Agonist Calcitriol For RXR/VDR heterodimers, neither honokiol or bexarotene alone increased the mRNA level of a VDR target gene, CYP24A1, in HEK293 cells, whereas both honokiol and bexarotene augmented the mRNA level of CYP24A1 by concurrent treatment with calcitriol $(0.1 \mu \mathrm{M})$ in a dose-dependent manner (Fig. 3A). When the dose-dependent effects of calcitriol were assessed in the presence or absence of rexinoids, calcitriol markedly potentiated the induction of CYP24A1 mRNA similarly in the presence of honokiol or bexarotene, but only at the slightly higher concentration of $10^{-7} \mathrm{M}$ (Fig. $3 B)$. Although the data are not shown, we confirmed that honokiol and bexarotene failed to activate VDR using a GAL4VDR binding assay.

Effects of Honokiol on the Induction of Proteins of NR Target Genes Since honokiol was found to synergistically induce the mRNA expressions of PPAR $\gamma, \mathrm{LXR}$, and VDR target genes in the presence of the respective agonists for the partner NRs of RXR heterodimers, we next evaluated the inductions of Angptl-4, ABCA1, and CYP24A1 proteins by honokiol. The protein levels of the three genes clearly reflected 
CYP24A1

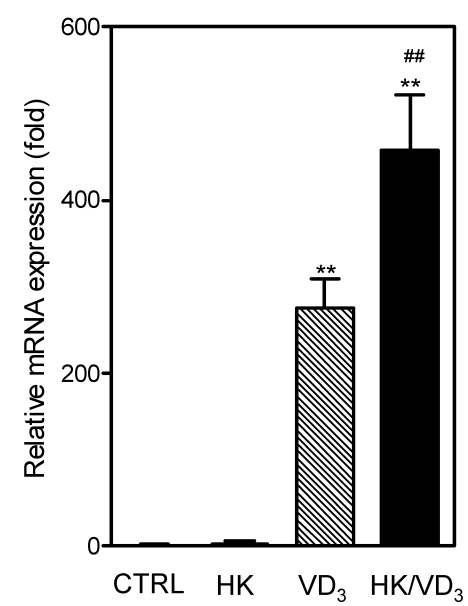

D9k

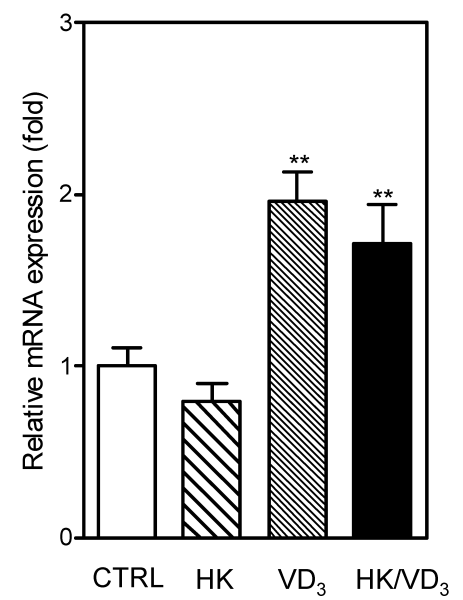

TRPV6

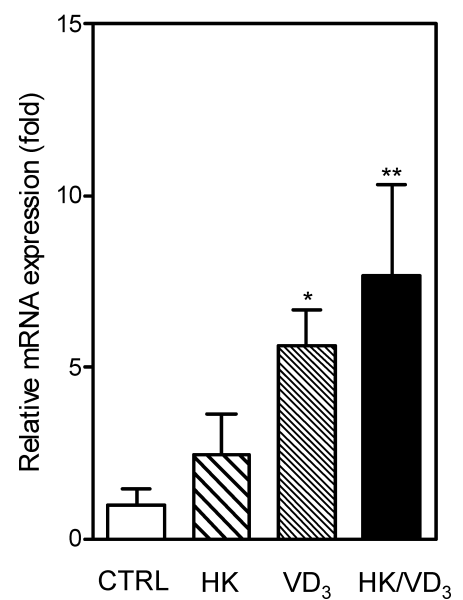

Fig. 7. Effects of Honokiol and a VDR Agonist on the Induction of VDR Target Genes in Caco-2 Cells

Caco-2 cells were treated with honokiol $(\mathrm{HK} ; 20 \mu \mathrm{M})$ or calcitriol $\left(\mathrm{VD}_{3} ; 0.1 \mu \mathrm{M}\right)$ alone or with a combination of HK $(20 \mu \mathrm{M})$ and $\mathrm{VD},(0.1 \mu \mathrm{M})$ for $24 \mathrm{~h}$. After the incubation, the mRNA levels of TRPV6, calbindin D9k, and CYP24A1 were measured by quantitative real-time RT-PCCR, normalized by the $\beta$-actin levels, and expressed as the fold inductions relative to the levels in vehicle-treated cells. The data shown are the means \pm S.D. of three wells from a representative of three independent experiments that produced similar results. ${ }^{*} p<0.05,{ }^{*} p<0.01 v s$. the vehicle control (CTRL); ${ }^{\#} p<0.01 v s$. the $\mathrm{VD}_{3}$ group.

their mRNA levels, since honokiol induced more Angptl-4, ABCA1, and CYP24A1 proteins by concurrent treatment with PPAR $\gamma$, LXR, and VDR agonists than by treatment with honokiol or the respective agonists alone (Fig. 4).

Effects of Honokiol and Rosiglitazone on the Induction of PPAR $\boldsymbol{\gamma}$ Target Genes in 3T3-L1 Adipocytes To assess the effects of honokiol on PPAR $\gamma$ target genes other than Angptl-4 or in different cells from HLE cells, adiponectin, glucose transporter-4 (GLUT4), and adipocyte fatty acid-binding protein-2 (aP2) were selected as PPAR $\gamma$ target genes. Although PPAR $\gamma$ is a permissive partner NR, honokiol alone failed to increase the mRNA levels of adiponectin, GLUT4, and aP2 in 3T3-L1 adipocytes (Fig. 5), similar to the case for Angptl-4. On the other hand, rosiglitazone alone was able to increase the mRNA levels of these three genes, and further accelerate their induction significantly and synergistically in combination with honokiol, when compared with the levels induced by rosiglitazone alone.

Effects of Honokiol and T0901317 on the Induction of LXR Target Genes in 3T3-L1 Adipocytes To assess the effects on LXR target genes, we examined the effects of honokiol on the mRNA levels of ABCA1, ABCG1, and apoE induced by T0901317. Although LXR is also a permissive partner NR, honokiol alone was not able to increase the mRNA levels of ABCA1, ABCG1, and apoE in 3T3-L1 adipocytes. However, honokiol was capable of enhancing the mRNA levels of ABCA1, ABCG1, and apoE synergistically with T0901317 $(1 \mu \mathrm{M})$ at a relatively low concentration, while T0901317 alone slightly or significantly increased these mRNA levels (Fig. 6).

Effects of Honokiol and Calcitriol on the Induction of VDR Target Genes in Caco-2 Cells To further evaluate the effects on VDR target genes, we examined the effects of honokiol on the expression levels of transient receptor potential vanilloid 6 (TRPV6), calbindin D9k, and CYP24A1 induced by calcitriol. Since VDR is considered to be a nonpermissive NR, honokiol alone had no effect on the mRNA levels of these genes, while the VDR agonist calcitriol significantly increased these levels. When the combined effects of honokiol and calcitriol were examined, honokiol was able to facilitate the transcription of CYP24A1, but not TRPV6 and calbindin D9k, induced by $0.1 \mu \mathrm{M}$ calcitriol (Fig. 7).

\section{DISCUSSION}

Our previous and present studies have demonstrated that honokiol is a naturally occurring rexinoid that does not activate $\mathrm{LXR}, \operatorname{PPAR} \gamma, \operatorname{PPAR} \delta$, or $\mathrm{RAR}$ in addition to $\mathrm{VDR} .{ }^{17)}$ Since honokiol was clearly identified as a novel rexinoid, we investigated its properties as a regulator of RXR heterodimers, in comparison with those of the synthetic rexinoid bexarotene. In the present study, we found that honokiol synergistically potentiated the activation of PPAR $\gamma / \mathrm{RXR}, \mathrm{RXR} /$ LXR, and RXR/VDR heterodimers by the respective agonists for the partner NRs, rosiglitazone, T0901317, and calcitriol, in 3T3-L1 adipocytes and HLE cells, although honokiol alone was not able to activate these RXR heterodimers. In contrast, bexarotene alone was capable of activating PPAR $\gamma / \mathrm{RXR}$ and RXR/LXR heterodimers, but not RXR/VDR heterodimers, consistent with the definition of permissive and nonpermissive partner NRs. Furthermore, it accelerated the activation of these three RXR heterodimers by the respective agonists for the partner NRs. When honokiol and bexarotene were compared for their rexinoid abilities in combination with the partner NR agonists, rosiglitazone was likely to activate PPAR $\gamma /$ RXR heterodimers more efficiently at lower doses in the presence of honokiol than bexarotene, both of which were used at different concentrations, but showed almost the same concentrations to reach a plateau for the activation of PPAR $\gamma /$ RXR heterodimers. These findings may indicate that honokiol possesses a property that can potentiate the activation of various RXR heterodimers by the respective agonists for the partner NRs, although it fails to activate RXR heterodimers on its own.

Honokiol alone was found to upregulate ABCA1 and ABCG1 mRNA levels in macrophage-like cell line RAW264.7 cells in our previous report. ${ }^{17)}$ Jung and coworkers also re- 
ported that honokiol induced ABCA1 mRNA in human glioma cell line U251-MG and THP-1 cells. ${ }^{18)}$ In the present study, we found that honokiol alone did not significantly increase the ABCA1 mRNA levels in HLE cells and 3T3-L1 adipocytes. Therefore, the effects of honokiol on the activation of at least RXR/LXR heterodimers or the induction of target gene transcription in the absence of agonists for the partner NRs are likely to depend on the cell type involved. The celldependency appears to stem from differences in the types and amounts of NRs or coregulators (coactivators and corepressors) expressed in the cells.

Recently, Széles and coworkers reported that a large number of genes regulated by PPAR or LXR agonists were not affected by RXR-specific agonists (rexinoids) or were regulated to lesser extents. ${ }^{19)}$ Furthermore, RXR agonists regulated only small portions of the RAR or VDR target genes. In the present study, honokiol was found to upregulate the VDR target gene CYP24A1 via heterodimers formed by RXR and the nonpermissive partner NR VDR in combination with calcitriol in HEK293 and Caco-2 cells, while no effects on the VDR target genes TRPV6 and calbindin D9k were seen in Caco-2 cells. These findings suggest that the effects of honokiol are likely to be gene-specific or depend on the context surrounding the promoter region of the target genes. Taken together, RXR permissiveness can be limited in cell- or gene-dependent manners, even among permissive partner NRs. On the other hand, Nishimaki-Mogami and coworkers reported that the synthetic rexinoids PA024 and HX630 have different abilities to activate LXR/RXR heterodimers and induce ABCA1 expression in macrophage cell lines. ${ }^{20)}$ These findings suggest that the effects of rexinoids on the activation of RXR heterodimers and the induction of target gene transcription are likely to also depend on the ligand structure, as evidenced by the differences in the properties of honokiol and bexarotene. Recent accumulating evidence indicates that subtle differences in the structures of rexinoids induce different receptor conformations, leading to differential coactivator recruitment and subsequent downstream effects on gene expression.

In the present study, we found that honokiol can facilitate transcription via RXR heterodimers with the permissive partner NRs PPAR $\gamma$ and LXR in combination with agonists for the partner NRs in 3T3-L1 adipocytes and HLE cells. These findings indicate that combinations of honokiol and agonists for the partner NRs may enhance the clinical value of honokiol. In fact, honokiol enhanced the effects of rosiglitazone on the activation of PPAR $\gamma$ target genes such as adiponectin, GLUT4, and aP2 in 3T3-L1 adipocytes, suggesting that honokiol synergistically stimulates the differentiation and function of adipocytes in combination with endogenous $\operatorname{PPAR} \gamma$ agonists that are produced in the early phase of preadipocyte differentiation or clinically administered PPAR $\gamma$ agonists. In addition, honokiol augmented the activity of the LXR agonist T0901317 for the induction of LXR target genes in 3T3-L1 adipocytes. Activation of LXR was reported to cause a switch between glucose and fatty acid oxidation, resulting in upregulation of mitochondrial $\beta$-oxidation in adipocytes. ${ }^{21,22)}$ Although the transcriptional activation of genes involved in glucose and fatty acid oxidation was not explored in this study, honokiol enhanced the activation of LXR target genes such as ABCA1, ABCG1, and apoE by the LXR agonist T0901317, suggesting that it may influence glucose and fatty acid oxidation in adi- pocytes. During the preparation of this manuscript, Choi and coworkers reported that honokiol enhances adipocyte differentiation of 3T3-L1 preadipocytes by increasing PPAR $\gamma 2$ mRNA expression and potentiating insulin signaling pathways such as the Ras/extracellular signal regulated kinase (ERK)1/2 and phosphoinositide-3-kinase/Akt signaling pathways. ${ }^{23)}$ AlonsoCastro and coworkers also reported that honokiol increased glucose uptake in murine and human adipocytes by stimulating insulin signaling pathways. ${ }^{24)}$ Collectively, these findings and our results strongly suggest that honokiol can efficiently stimulate 3T3-L1 cell differentiation via multiple pathways, including RXR activation, resulting in enhanced insulin sensitivity or protection against obesity.

CYP24A1 is an enzyme that hydroxylates active vitamin $\mathrm{D}, 1 \alpha, 25$-dihydroxyvitamin $\mathrm{D}_{3}\left(1 \alpha, 25(\mathrm{OH})_{2} \mathrm{D}_{3}\right)$, to render it inactive. On the other hand, CYP24A1 is induced by both $1 \alpha, 25(\mathrm{OH})_{2} \mathrm{D}_{3}$ and 25-hydroxyvitamin $\mathrm{D}_{3}$, and is one of the most highly inducible genes. Therefore, honokiol can only facilitate the transcription of CYP24A1 induced by calcitriol, because it is highly responsive to VDR signaling. ${ }^{25)}$ CYP24A1 plays a critical role in regulating the physiological concentration of $1 \alpha, 25(\mathrm{OH})_{2} \mathrm{D}_{3}$. Given that vitamin $\mathrm{D}$ is involved in a wide array of physiological functions, such as calcium homeostasis, bone mineralization, growth control, differentiation, cognition, and immune responses, ${ }^{26-28)}$ honokiol may affect vitamin D functions in the kidney to provide versatile effects on physiological or pathophysiological systems.

Based on the findings of the present study, combination therapies using honokiol and partner NR agonists are expected to exhibit versatile beneficial effects on not only diabetes, insulin resistance, atherosclerosis, and cancer as reported for synthetic rexinoids, ${ }^{29,30)}$ but also the respective side effects intrinsic to PPAR $\gamma$ and VDR agonists. Specifically, the therapeutic effects of the PPAR $\gamma$ agonists thiazolidinediones and VDR agonist $1 \alpha, 25(\mathrm{OH})_{2} \mathrm{D}_{3}$ are hampered by their severe side effects. $^{31,32)}$ On the other hand, honokiol has been well tolerated in models of arthritis, heart disease, and cancer, ${ }^{33,34)}$ and has been used without noticeable side effects for many years in traditional Japanese or Chinese medicines. ${ }^{35)}$ Therefore, combination therapies using honokiol and low doses of the respective agonists may overcome such problems.

To date, honokiol has been shown to exert many pharmacological effects, including anti-inflammatory, ${ }^{36)}$ anti-arrhythmic, ${ }^{37)}$ anxiolytic, ${ }^{35)}$ antitumor, ${ }^{33)}$ antithrombotic, ${ }^{38)}$ antiarthritic $^{34)}$ and anti-allergic ${ }^{39)}$ effects. However, the molecular targets underlying the numerous activities of honokiol have been poorly understood.

As only one of such molecular targets, honokiol and its isomer magnolol have been reported to bind to $\gamma$-aminobutyric acid $\left(\mathrm{GABA}_{\mathrm{A}}\right)$ receptors and allosterically increase the affinity of these receptors for GABA. ${ }^{40,41)}$ GABA is known to have acute inhibitory actions on both activated $T$ cell function and $\mathrm{T}$ cell proliferation through $\mathrm{GABA}_{\mathrm{A}}$ receptors. These immunomodulatory effects via $\mathrm{GABA}_{\mathrm{A}}$ receptors are closely involved in the suppression of allergic asthma and type 1 diabetes in NOD mice by GABA. ${ }^{42,43)}$ Therefore, it is possible that the anti-allergic effects of honokiol are produced through modulation of $\mathrm{GABA}_{\mathrm{A}}$ receptors. In our study, RXR was identified as a molecular target of honokiol. Bexarotene is a clinically available antitumor agent, whose underlying mechanism is considered to involve suppression of tumor proliferation via 
RXR/RXR homodimers or RXR/RAR heterodimers. These observations suggest that the antitumor activity of honokiol is related to its RXR agonist activity. Furthermore, it was recently reported that the RXR agonist 9-cis-retinoic acid exerts anti-inflammatory effects by directly suppressing nuclear factor-kappa B (NF- $\kappa$ B) binding to the NF- $\kappa$ B sites in the promoter regions of some inflammatory cytokines via $\mathrm{RXR} .{ }^{44)}$ These observations also suggest that the anti-inflammatory effects of honokiol may result from inhibition of NF- $\kappa \mathrm{B}$ via an RXR-dependent mechanism. Therefore, some of the biological and pharmacological activities of honokiol reported to date are likely to be explained by mechanisms involving RXR activation, although it remains to be determined which RXR heterodimers or homodimers are involved.

Finally, we need to further clarify the differences in properties between honokiol and other synthetic rexinoids. Such detailed studies should enable clinical applications of honokiol for the prevention and treatment of lifestyle-related and other diseases.

\section{REFERENCES}

1) Mangelsdorf DJ, Ong ES, Dyck JA, Evans RM. Nuclear receptor that identifies a novel retinoic acid response pathway. Nature, $\mathbf{3 4 5}$, 224-229 (1990)

2) Mangelsdorf DJ, Thummel C, Beato $M$, Herrlich P, Schütz G, Umesono K, Blumberg B, Kastner P, Mark M, Chambon P, Evans RM. The nuclear receptor superfamily: the second decade. Cell, 83, 835-839 (1995).

3) Magelsdorf DJ, Borgmeyer U, Heyman RA, Zhou JY, Ong ES, Oro AE, Kakizuka A, Evans RM. Characterization of three RXR genes that mediate the action of 9-cis retinoic acid. Genes Dev., 6 , 329-344 (1992).

4) Mangelsdorf DJ, Evans RM. The RXR heterodimers and orphan receptors. Cell, 83, 841-850 (1995).

5) Forman BM, Umesono K, Chen J, Evans RM. Unique response pathways are established by allosteric interactions among nuclear hormone receptors. Cell, 81, 541—550 (1995).

6) Botling J, Castro DS, Öberg F, Nilsson K, Perlmann T. Retinoic acid receptor/retinoid $\mathrm{X}$ receptor heterodimers can be activated through both subunits providing a basis for synergistic transactivation and cellular differentiation. J. Biol. Chem., 272, 9443-9449 (1997).

7) Li D, Li T, Wang F, Tian H, Samuels HH. Functional evidence for retinoid X receptor (RXR) as a nonsilent partner in the thyroid hormone receptor/RXR heterodimer. Mol. Cell. Biol., 22, 5782-5792 (2002).

8) Bettoun DJ, Burris TP, Houck KA, Buck DW 2nd, Stayrook KR, Khalifa B, Lu J, Chin WW, Nagpal S. Retinoid X receptor is a nonsilent major contributor to vitamin D receptor-mediated transcriptional activation. Mol. Endocrinol., 17, 2320-2328 (2003).

9) Mukherjee R, Davies PJA, Crombie DL, Bischoff ED, Cesario RM, Jow L, Hamann LG, Boehm MF, Mondon CE, Nadzan AM, Paterniti JR Jr, Heyman RA. Sensitization of diabetic and obese mice to insulin by retinoid $X$ receptor agonists. Nature, 386, 407-410 (1997).

10) Lalloyer F, Fiévet C, Lestavel S, Torpier G, van der Veen J, Touche V, Bultel S, Yous S, Kuipers F, Paumelle R, Fruchart JC, Staels B, Tailleux A. The RXR agonist bexarotene improves cholesterol homeostasis and inhibits atherosclerosis progression in a mouse model of mixed dyslipidemia. Arterioscler. Thromb. Vasc. Biol., 26, 2731-2737 (2006)

11) Levin AA, Sturzenbecker LJ, Kazmer S, Bosakowski T, Huselton C, Allenby G, Speck J, Kratzeisen C, Rosenberger M, Lovey A, Grippo JF. 9-cis retinoic acid stereoisomer binds and activates the nuclear receptor RXR alpha. Nature, 355, 359-361 (1992).

12) de Urquiza AM, Liu S, Sjöberg M, Zetterström RH, Griffiths W, Sjövall J, Perlmann T. Docosahexaenoic acid, a ligand for the retinoid X receptor in mouse brain. Science, 290, 2140-2144 (2000).

13) Kitareewan S, Burka LT, Tomer KB, Parker CE, Deterding LJ, Stevens RD, Forman BM, Mais DE, Heyman RA, McMorris T, Weinberger C. Phytol metabolites are circulating dietary factors that activate the nuclear receptor RXR. Mol. Biol. Cell, 7, 1153-1166 (1996).

14) Pinaire JA, Reifel-Miller A. Therapeutic potential of retinoid $x$ receptor modulators for the treatment of the metabolic syndrome. PPAR Res., 2007, 94156 (2007).

15) Liu S, Ogilvie KM, Klausing K, Lawson MA, Jolley D, Li D, Bilakovics J, Pascual B, Hein N, Urcan M, Leibowitz MD. Mechanism of selective retinoid $\mathrm{X}$ receptor agonist-induced hypothyroidism in the rat. Endocrinology, 143, 2880-2885 (2002).

16) Lenhard JM, Lancaster ME, Paulik MA, Weiel JE, Binz JG, Sundseth SS, Gaskill BA, Lightfoot RM, Brown HR. The RXR agonist LG100268 causes hepatomegaly, improves glycaemic control and decreases cardiovascular risk and cachexia in diabetic mice suffering from pancreatic beta-cell dysfunction. Diabetologia, 42, 545 -554 (1999).

17) Kotani H, Tanabe H, Mizukami H, Makishima M, Inoue M. Identification of a naturally occurring rexinoid, honokiol, that activates the retinoid X receptor. J. Nat. Prod., 73, 1332-1336 (2010).

18) Jung CG, Horike H, Cha BY, Uhm KO, Yamauchi R, Yamaguchi T, Hosono T, Iida K, Woo JT, Michikawa M. Honokiol increases ABCA1 expression level by activating retinoid $\mathrm{X}$ receptor beta. Biol. Pharm. Bull., 33, 1105-1111 (2010).

19) Széles L, Póliska S, Nagy G, Szatmari I, Szanto A, Pap A, Lindstedt M, Santegoets SJAM, Rühl R, Dezsö B, Nagy L. Research resource: transcriptome profiling of genes regulated by RXR and its permissive and nonpermissive partners in differentiating monocytederived dendritic cells. Mol. Endocrinol., 24, 2218-2231 (2010).

20) Nishimaki-Mogami T, Tamehiro N, Sato Y, Okuhira K, Sai K, Kagechika H, Shudo K, Abe-Dohmae S, Yokoyama S, Ohno Y, Inoue K, Sawada J. The RXR agonists PA024 and HX630 have different abilities to activate LXR/RXR and to induce ABCA1 expression in macrophage cell lines. Biochem. Pharmacol., 76, 1006-1013 (2008).

21) Stenson BM, Rydén M, Steffensen KR, Wåhlén K, Pettersson AT, Jocken JW, Arner P, Laurencikiene J. Activation of liver X receptor regulates substrate oxidation in white adipocytes. Endocrinology, 150, 4104-4113 (2009).

22) Stenson BM, Rydén M, Venteclef N, Dahlman I, Pettersson AML, Mairal A, Aström G, Blomqvist L, Wang V, Jocken JWE, Clément K, Langin D, Arner P, Laurencikiene J. Liver X receptor (LXR) regulates human adipocyte lipolysis. J. Biol. Chem., 286, 370-379 (2011).

23) Choi SS, Cha BY, Iida K, Sato M, Lee YS, Teruya T, Yonezawa T, Nagai K, Woo JT. Honokiol enhances adipocyte differentiation by potentiating insulin signaling in 3T3-L1 preadipocytes. $J$. Nat. Med., 65, 424-430 (2011).

24) Alonso-Castro AJ, Zapata-Bustos R, Domínguez F, García-Carrancá A, Salazar-Olivo LA. Magnolia dealbata Zucc and its active principles honokiol and magnolol stimulate glucose uptake in murine and human adipocytes using the insulin-signaling pathway. Phytomedicine, 18, 926-933 (2011).

25) Schuster I. Cytochromes P450 are essential players in the vitamin D signaling system. Biochim. Biophys. Acta, 1814, 186-199 (2011).

26) Holick MF. Vitamin D and bone health. J. Nutr., 126 (Suppl.), 1159S-1164S (1996)

27) Mora JR, Iwata M, von Andrian UH. Vitamin effects on the immune system: vitamins A and D take centre stage. Nat. Rev. Immunol., 8, 685-698 (2008).

28) Tang J, Zhou R, Luger D, Zhu W, Silver PB, Grajewski RS, Su SB, Chan CC, Adorini L, Caspi RR. Calcitriol suppresses antiretinal 
autoimmunity through inhibitory effects on the Th17 effector response. J. Immunol., 182, 4624-4632 (2009).

29) Shen Q, Cline GW, Shulman GI, Leibowitz MD, Davies PJA. Effects of rexinoids on glucose transport and insulin-mediated signaling in skeletal muscles of diabetic (db/db) mice. J. Biol. Chem., 279, 19721-19731 (2004).

30) Claudel T, Leibowitz MD, Fiévet C, Tailleux A, Wagner B, Repa JJ, Torpier G, Lobaccaro JM, Paterniti JR, Mangelsdorf DJ, Heyman RA, Auwerx J. Reduction of atherosclerosis in apolipoprotein E knockout mice by activation of the retinoid $\mathrm{X}$ receptor. Proc. Natl. Acad. Sci. U.S.A., 98, 2610-2615 (2001).

31) Rubenstrunk A, Hanf R, Hum DW, Fruchart JC, Staels B. Safety issues and prospects for future generations of PPAR modulators. Biochim. Biophys. Acta, 1771, 1065-1081 (2007).

32) Smith DC, Johnson CS, Freeman CC, Muindi J, Wilson JW, Trump DLA. A Phase I trial of calcitriol (1,25-dihydroxycholecalciferol) in patients with advanced malignancy. Clin. Cancer Res., 5, 13391345 (1999).

33) Konoshima T, Kozuka M, Tokuda H, Nishino H, Iwashima A, Haruna M, Ito K, Tanabe M. Studies on inhibitors of skin tumor promotion, IX. Neolignans from Magnolia officinalis. J. Nat. Prod., 54, 816-822 (1991).

34) Munroe ME, Arbiser JL, Bishop GA. Honokiol, a natural plant product, inhibits inflammatory signals and alleviates inflammatory arthritis. J. Immunol., 179, 753-763 (2007).

35) Kim BH, Cho JY. Anti-inflammatory effect of honokiol is mediated by PI3K/Akt pathway suppression. Acta Pharmacol. Sin., 29, 113-122 (2008).

36) Tsai SK, Huang CH, Huang SS, Hung LM, Hong CY. Antiarrhythmic effect of magnolol and honokiol during acute phase of coronary occlusion in anesthetized rats: influence of L-NAME and aspirin.
Pharmacology, 59, 227-233 (1999).

37) Maruyama Y, Kuribara H, Morita M, Yuzurihara M, Weintraub ST. Identification of magnolol and honokiol as anxiolytic agents in extracts of saiboku-to, an oriental herbal medicine. J. Nat. Prod., 61, 135-138 (1998).

38) $\mathrm{Hu} \mathrm{H}$, Zhang XX, Wang YY, Chen SZ. Honokiol inhibits arterial thrombosis through endothelial cell protection and stimulation of prostacyclin. Acta Pharmacol. Sin., 26, 1063-1068 (2005).

39) Han SJ, Bae EA, Trinh HT, Yang JH, Youn UJ, Bae KH, Kim DH. Magnolol and honokiol: inhibitors against mouse passive cutaneous anaphylaxis reaction and scratching behaviors. Biol. Pharm. Bull., 30, 2201-2203 (2007).

40) Ai J, Wang X, Nielsen M. Honokiol and magnolol selectively interact with GABAA receptor subtypes in vitro. Pharmacology, 63, 34-41 (2001).

41) Squires RF, Ai J, Witt MR, Kahnberg P, Saederup E, Sterner O, Nielsen M. Honokiol and magnolol increase the number of $[3 \mathrm{H}]$ muscimol binding sites three-fold in rat forebrain membranes in vitro using a filtration assay, by allosterically increasing the affinities of low-affinity sites. Neurochem. Res., 24, 1593-1602 (1999).

42) Munroe ME, Businga TR, Kline JN, Bishop GA. Anti-inflammatory effects of the neurotransmitter agonist Honokiol in a mouse model of allergic asthma. J. Immunol., 185, 5586-5597 (2010).

43) Tian J, Lu Y, Zhang H, Chau CH, Dang HN, Kaufman DL. Gamma-aminobutyric acid inhibits $\mathrm{T}$ cell autoimmunity and the development of inflammatory responses in a mouse type 1 diabetes model. J. Immunol., 173, 5298-5304 (2004).

44) Lee HC, Headley MB, Iseki M, Ikuta K, Ziegler SF. Cutting edge: Inhibition of NF-kappaB-mediated TSLP expression by retinoid $\mathrm{X}$ receptor. J. Immunol., 181, 5189—5193 (2008). 